\title{
Effects of soil composition and mineralogy on the bioaccessibility of arsenic from tailings and soil in gold mine districts of Nova Scotia
}

Louise Meunier ${ }^{\dagger}$, Stephen R. Walker ${ }^{\ddagger}$, Joanna Wragg ${ }^{\S}$, Michael B. Parsons ${ }^{\wedge}$, Iris Koch ${ }^{\dagger}$, Heather E. Jamieson ${ }^{\ddagger}$ Kenneth J. Reimer ${ }^{*} \dagger$

$\dagger$ Environmental Sciences Group, Royal Military College, Kingston, Ontario K7K7B4, Canada $\ddagger$ Department of Geological Sciences and Geological Engineering, Queen’s University, Kingston, Ontario K7L3N6, Canada

$\S$ British Geological Survey, Keyworth, Nottingham NG125GG, United Kingdom

${ }^{\wedge}$ Natural Resources Canada, Geological Survey of Canada (Atlantic), 1 Challenger Drive, Dartmouth, Nova Scotia, B2Y4A2, Canada

*Corresponding author phone: (613)541-6000, ext 6161; fax: (613)541-6596; e-mail: reimerk@rmc.ca. 


\begin{abstract}
Bioaccessibility tests and mineralogical analyses were performed on arsenic-contaminated tailings and soils from gold mine districts of Nova Scotia, Canada, to examine the links between soil composition, mineralogy and arsenic bioaccessibility. Arsenic bioaccessibility ranges from $0.1 \%$ to $49 \%$. A weak correlation was observed between total and bioaccessible arsenic concentrations, and the arsenic bioaccessibility was not correlated with other elements. Bulk Xray absorption near-edge structure analysis shows arsenic in these near-surface samples is mainly in pentavalent form, indicating that most of the arsenopyrite $\left(\mathrm{As}^{1-}\right)$ originally present in the tailings and soils has been oxidized during weathering reactions. Detailed mineralogical analyses of individual samples identified up to seven arsenic species, the relative proportions of which appear to affect arsenic bioaccessibility. The highest arsenic bioaccessibility (up to 49\%) is associated with the presence of calcium-iron arsenate. Samples containing arsenic predominantly as arsenopyrite or scorodite have the lowest bioaccessibility $(<1 \%)$. Other arsenic species identified (predominantly amorphous iron arsenates and arsenic-bearing iron(oxy)hydroxides) are associated with intermediate bioaccessibility ( 1 to $10 \%)$. The presence of a more soluble arsenic phase, even at low concentrations, results in increased arsenic bioaccessibility from the mixed arsenic phases associated with tailings and mine-impacted soils.
\end{abstract}




\section{Introduction}

Gold mines were in operation in the province of Nova Scotia, on the eastern coast of Canada, from the 1860 s to the mid-1940s (1). During this time, naturally occurring arsenopyrite was processed and deposited with some three million tonnes of mine tailings within 64 gold-mining districts in Nova Scotia (2). Post-depositional erosion and weathering processes have redistributed and oxidized most of the near-surface $(0-10 \mathrm{~cm})$ arsenic-rich tailings. Samples of tailings collected in Nova Scotia have arsenic concentrations ranging from $9.0 \mathrm{mg} \cdot \mathrm{kg}^{-1}$ to $310,000 \mathrm{mg} \cdot \mathrm{kg}^{-1}(31 \mathrm{wt} \%),\left(n=433 ;\right.$ mean $\left.=10,000 \mathrm{mg} \cdot \mathrm{kg}^{-1}\right)(3), 99$ percent of which exceed the local regulatory level of $12 \mathrm{mg} \cdot \mathrm{kg}^{-1}$ (4). The presence of a contaminant in excess of these guidelines may prompt a risk assessment (5), especially when the sampled locations are adjacent to residential properties and used for recreational activities, such as in Nova Scotia. A major pathway contributing to human health risk, especially in children, is incidental soil ingestion (6). Once ingested, a portion of the arsenic may solubilise (i.e. become bioaccessible) in the gastrointestinal tract, and some of this may be absorbed (i.e. become bioavailable) into systemic circulation (7). The solubilised arsenic forms (predominantly trivalent and pentavalent arsenic compounds) are known to be toxic and carcinogenic (8). Estimating the bioaccessibility of arsenic from site-specific soil samples provides a more accurate approximation of the relevant dose, and as such is an important component of risk assessment (9).

In this study, the bioaccessibility of arsenic was determined using an in-vitro physiologicallybased extraction test (PBET). This method is based on Ruby et al. (10) and Rodriguez et al. (6), and is similar to previously published tests $(11,12)$. For arsenic-contaminated mine waste 
samples, results obtained using a similar PBET were well correlated to in-vivo (rats and cattle) bioavailability (13). Wide variations in arsenic bioaccessibility from previous PBET studies (from 0.50 to $66 \mathrm{wt} \%$ ) may be attributed to soil elemental composition and arsenic speciation (7, 14). This variability can also result from a number of parameters, including the $\mathrm{pH}$ of the simulated solution (10), the chosen liquid-to-solid ratio (15), and sample particle size (16). Such variability introduces uncertainty concerning the relevance of bioaccessibility measurements (9) and limits the acceptance of bioaccessibility measurements by end users and regulators (17).

Furthermore, the effect of mineralogical composition on arsenic bioaccessibility has not been thoroughly determined, and previous studies have focussed on pure mineral forms and model soils. Arsenic sulphides (e.g. arsenopyrite FeAsS) are among the least bioaccessible forms of arsenic from soil $(<1 \%)$ (7). Iron-arsenic oxides (especially amorphous iron oxides and hydroxides) tend to have intermediate bioaccessibility $(<5 \%)(18)$, and arsenic trioxide is considered comparatively more bioaccessible (7). The solubility of arsenic-bearing minerals may be influenced by encapsulation or coating of grains, affecting their bioaccessibility $(7,17)$, and the presence of dissolved organic carbon may promote the solubility of arsenic in soils (19).

The present study focussed on the multiple arsenic mineral forms present in the arsenic-enriched tailings and soils of abandoned gold mine sites. The first objective was to assess the influence of various PBET method parameters (e.g. liquid-to-solid ratio, particle size) in evaluating the bioaccessibility of arsenic in mine tailings and soils. The second objective was to determine the extent to which soil composition (organic carbon, elemental composition) and arsenic mineralogy (oxidation state(s), bulk and detailed speciation) affect the bioaccessibility of arsenic. 
X-ray Absorption Near-Edge Structure (XANES) analysis was used to determine the oxidation state(s) of arsenic, and detailed speciation information was obtained through conventional and synchrotron-based techniques including micro-X-ray fluorescence $(\mu-\mathrm{XRF})$ and diffraction $(\mu-$ XRD).

\section{Experiments}

Sample description. The samples selected for this study were collected from surface tailings and soils overlying mineralized bedrock from six abandoned gold mines in Nova Scotia. Of the 29 samples collected in 2005, five each were from the Caribou (denoted CAR), Montague (MG), and Goldenville (GD) districts, 12 samples were collected from the North Brookfield (NB) district, and a single sample from the Oldham (OLD) and Whiteburn (WB) districts respectively. In these deposits, arsenic was originally present as arsenopyrite in gold-bearing quartz veins and the surrounding bedrock. Gold was recovered through stamp mills with mercury amalgamation, gravity separation and cyanidation (20). In addition, roasting was used at the North Brookfield site prior to oxidative chlorination (21). The samples are primarily tailings with three forest soils included for comparison (MG6, NB12 and NB13). Sample descriptions are provided in Supporting Information (SI), Table S1.

Sample preparation and analyses. Samples were air-dried at $35{ }^{\circ} \mathrm{C}$ and dry-sieved to $<150$ $\mu \mathrm{m}$, which includes the particle size that is likely to remain on the hands of children (22) and be incidentally ingested. The bulk and $<150 \mu \mathrm{m}$ particle size fractions for each sample were analyzed for major and trace elements via inductively-coupled plasma mass spectrometry (ICPMS) following an aqua regia digestion as described by Parsons et al. (3). 
For synchrotron bulk XANES analysis, a subsample of the $<150 \mu \mathrm{m}$ particle size fraction was spread on Kapton ${ }^{\circledR}$ tape and mounted in four layers on an aluminum sample holder. Undiluted solid standards of arsenic trioxide $\left(\mathrm{As}_{2} \mathrm{O}_{3}\right.$, Fluka, reagent grade), potassium arsenate $\left(\mathrm{KH}_{2} \mathrm{AsO}_{4}\right.$, Fluka reagent grade), yukonite $\left(\mathrm{Ca}_{2} \mathrm{Fe}_{3}\left(\mathrm{AsO}_{4}\right)_{3}(\mathrm{OH})_{4} \bullet 4 \mathrm{H}_{2} \mathrm{O}\right.$, M990, Queen's University Miller Museum of Geology), scorodite $\left(\mathrm{FeAsO}_{4} \cdot 2 \mathrm{H}_{2} \mathrm{O}, \mathrm{M} 6306\right.$, Queen's University), and arsenopyrite (Ward's Natural Science) were similarly prepared. The XANES spectra of selected samples $(n=$ 13) and standards were collected at room temperature at the Advanced Photon Source (APS) Pacific Northwest Consortium/X-ray Operations and Research (PNC/XOR) bending magnet facility in transmission and fluorescence mode and analyzed as described by Smith et al. (23). Details of the mineralogical characterization (petrography, electron micro-probe) and synchrotron micro-analysis $(\mu-\mathrm{XRF}, \mu-\mathrm{XRD})$ conducted on thin sections at the National Synchrotron Light Source (NSLS) beamline X26A are provided in Walker et al. (24). In the case of sample NB1, an uncoated thin section was inspected for arsenic phases using a Zeiss Evo 50 environmental scanning electron microscope (ESEM) with an Oxford Inca Energy 450 X-ray detector.

Bioaccessibility extraction. Bioaccessibility tests were performed on the $<150 \mu \mathrm{m}$ particle size fraction of each sample. Two subsamples were tested for each sample: one in the gastric phase (hereafter denoted P1), and one in the gastric followed by intestinal phase (hereafter denoted P2). All samples were tested at a liquid-to-solid ratio of 100:1 and secured in a temperature-controlled flatbed rotation incubator (New Brunswick Scientific Innova 4230) at $37{ }^{\circ} \mathrm{C}$ and at $150 \mathrm{rpm}$ under aerobic conditions. The PBET solution composition is described by Koch et al. (12) and 
was acidified with hydrochloric acid (Fisher, reagent grade) to a $\mathrm{pH}$ of $1.80 \pm 0.05$ (Accumet Excel XL15 pH probe). The $\mathrm{pH}$ was measured after 30 minutes (and acidified as required), and again at the end of the one-hour gastric phase. The time taken to measure $\mathrm{pH}$ (less than six minutes per sample) was included in the overall incubation time. Once the gastric phase was completed, P1 subsamples were centrifuged $(3800 \mathrm{rpm}=2970 \bullet \mathrm{g} ; 20 \mathrm{~min})$, and filtered $(0.45 \mu \mathrm{m}$, PVDF membrane, Millipore). At the beginning of the four-hour intestinal phase, the $\mathrm{pH}$ of the gastric solution in the remaining subsamples (P2) was raised to $7.0 \pm 0.2$ with a saturated $\mathrm{Na}_{2} \mathrm{CO}_{3}$ (Fluka, reagent grade) solution and adjusted as required after two hours. At the end of the experiment, P2 subsamples were centrifuged and filtered as described for the P1 subsamples.

Selected samples $(n=12)$ were tested at liquid-to-solid ratios up to 5000:1. At these ratios, only one extraction was prepared per sample, and an aliquot of solution was removed by syringe, filtered (0.45 $\mu \mathrm{m}$, PVDF membrane, Millipore) at the end of the gastric phase, and replaced with fresh PBET solution (reversing the filter to ensure no loss of solids), restoring the appropriate liquid-to-solid ratio. A second aliquot was collected after completing the intestinal phase as described for the 100:1 experiments. Sample aliquots were diluted with 2\% nitric acid (Fisher, trace metal grade) solution for analysis of total arsenic as described by Koch et al. (25).

All samples were extracted in random order in batches of 9 to 12, which included three duplicates, one blank and one standard reference material: NIST 2710, which is a contaminated soil with elevated trace element concentrations (26) for each phase. Arsenic concentrations were determined by ICP-MS (Thermo Electron Corporation X-Series ${ }^{I I}$ ) in collision cell mode as described by Smith et al. (27). All blanks were below the limit of quantification of $3 \mu \mathrm{g} \cdot \mathrm{L}^{-1}$. All 
standard reference material results were within laboratory control limits (SI, Table S2). The average of the relative percent difference (RPD) between the extraction duplicates was $7.2 \%$.

Bioaccessibility results are reported as either a concentration or percent value. The bioaccessible arsenic concentration corresponds to the quantity of arsenic extracted (in $\mathrm{mg}$ ) from each $\mathrm{kg}$ of sample (dry weight). Dividing the bioaccessible arsenic concentration by the total arsenic concentration in a given sample and multiplying this quotient by $100 \%$ yields the percent arsenic bioaccessibility.

\section{Results and Discussion}

The 29 samples have distinct visual and physical characteristics that represent the variability in near-surface tailings and soils encountered at the mining sites (SI, Table S1). On average, the < $150 \mu \mathrm{m}$ particle size fraction makes up less than $19 \mathrm{wt} \%$ of the bulk material in these samples. A notable exception is sample GD5, which is mainly composed of fine, silt-sized particles (typically $<20 \mu \mathrm{m}$ ). Of the three soil samples, two (MG6, NB13) contain the lowest concentration of arsenic $\left(<320 \mathrm{mg} \cdot \mathrm{kg}^{-1}\right)$ in the whole dataset. The third soil sample, NB12, was collected near a former (1886-1906) roasting and chlorination plant and has a much higher arsenic concentration $\left(9200 \mathrm{mg} \bullet \mathrm{kg}^{-1}\right)$. Samples CAR2 and GD1 represent mill concentrate residue and contain very high arsenic concentrations ( $>200,000 \mathrm{mg} \bullet \mathrm{kg}^{-1}, 20 \mathrm{wt} \%$ ). Seven tailings samples from North Brookfield are low in arsenic $\left(<1000 \mathrm{mg} \mathrm{kg}^{-1}\right)$ relative to the other sites, but four samples, NB6B, NB6C, NB11A, and NB11B were collected from a smaller tailings area near the processing plant and have a higher arsenic concentration $\left(>4000 \mathrm{mg} \bullet \mathrm{kg}^{-1}\right)$. 
The Oldham and Whiteburn tailings samples are similar in composition and arsenic concentration to those collected in Goldenville and Montague (3).

Bioaccessibility Results: Total arsenic concentrations in the 29 samples tested range from 320 to $310,000 \mathrm{mg} \cdot \mathrm{kg}^{-1},(31 \mathrm{wt} \%)$ The measured bioaccessible arsenic concentrations from these samples are much lower than the total arsenic concentrations, and ranged from 8.0 to 3400 $\mathrm{mg} \cdot \mathrm{kg}^{-1}$ in the gastric phase (P1), and 4.0 to $3900 \mathrm{mg} \bullet \mathrm{kg}^{-1}$ in the gastric followed by intestinal phase (P2). The bioaccessibility results are summarized in Table 1, and in Figure S1 (SI). The average percent arsenic bioaccessibility was relatively low at $13 \%$ (range from 0.1 to $49 \%$, median $8.4 \%$ ), which is similar to the results obtained for arsenic mine tailings by Palumbo-Roe and Klinck (28) (0.6 to $61 \%$, median 5.0\%). The present results are also consistent with previous bioavailability results, which show that arsenic from soils can be one-fifth as bioavailable as synthesized forms of arsenic (e.g. disodium arsenate heptahydrate $\left(\mathrm{Na}_{2} \mathrm{AsO}_{4} \cdot 7 \mathrm{H}_{2} \mathrm{O}\right)(29,30)$.

Effect of extraction phase, liquid-to-solid ratios and particle size. To address the issues of variations in bioaccessibility results, which may be attributed to the choice of liquid-to-solid ratios and particle size, the validity of the bioaccessibility results of the present study is first examined based on the influence of these parameters.

For 89 percent of the samples tested, arsenic bioaccessibility is greater in P2 than in P1 (Table 1), although the variation in percent arsenic bioaccessibility ( $\mathrm{P} 2-\mathrm{P} 1)$ is less than $10 \%$ in all cases except NB12 (11\%) and WB1 (16\%). The higher bioaccessibility in P2 most likely indicates that arsenic-bearing phases in these samples dissolved to a greater extent at the neutral 
extraction $\mathrm{pH}$ of $\mathrm{P} 2$. Arsenic minerals that formed through weathering under acidic conditions are likely more susceptible to dissolution at higher $\mathrm{pH}(14,31)$, such as that found in $\mathrm{P} 2$. These findings may reflect the result of this weathering phenomenon. Indeed, arsenic-bearing minerals in many of the tailings samples likely formed under acidic conditions (24), the exceptions being samples observed to contain calcium carbonates (see further discussion below). From a risk assessment perspective, the higher result of either P1 or P2 is chosen as a conservative estimate of bioaccessibility, (although P2 simulates the intestinal conditions under which systemic absorption occurs).

A comparison between bioaccessible arsenic (using the highest of either P1 or P2 results) and total arsenic concentrations from Table 1 reveals that the percent bioaccessibility is generally lower in the samples with greater arsenic concentrations (as shown in Figure S1), and this correlation is statistically significant $(n=29, r=0.3, p=0.002)$. This could indicate solution saturation with respect to arsenic-bearing phases (9). To investigate the possibility of saturation, tests were performed at various liquid-to-solid ratios on 13 samples representing a range of arsenic concentrations and bioaccessibilities. Bioaccessibility results (Figure 1) were consistent over the range of liquid-to-solid ratios (1-way ANOVA, $p>0.54$ ), demonstrating the repeatability of the method, and confirming the results of the 100:1 liquid-to-solid ratio as the percent arsenic bioaccessibility results did not increase at higher ratios. The largest variation between ratios is noted for sample GD5: the percent arsenic bioaccessibility varied between 33\% and $48 \%$, corresponding to an RPD of $26 \%$. This RPD is considered acceptable for duplicate analyses and may be attributed to the more reactive nature of this sample relative to others tested during this study. Therefore, the arsenic bioaccessibility results for these samples are insensitive 
to different liquid-to-solid ratios, and the 100:1 ratio is considered to be an acceptable liquid-tosolid ratio.

The effect of selected particle size could not be studied for the specific sample set described here because of the limited quantity of sample material. Nevertheless, a parallel study was conducted on a similar sample set collected from the Goldenville and Montague districts in 2006. Results (Figure S2, SI) show that arsenic bioaccessibility varies between the $<45 \mu \mathrm{m},<150 \mu \mathrm{m}$, and $<$ $250 \mu \mathrm{m}$ particle size fractions within each sample. However no systematic variation attributes a greater arsenic bioaccessibility with a specific particle size fraction, and the results indicate that there is no statistically significant differences in bioaccessibility between the three particle size fractions. Further tests should be conducted to determine the particle size range deemed most appropriate for assessing risk from ingestion (16). However, based on the current findings, the $<$ $150 \mu \mathrm{m}$ particle size fraction was retained as representative for the purposes of the present study.

The next step was to examine the effects of soil composition on bioaccessibility measurements. The organic carbon content and soil elemental composition were investigated first, followed by the bulk mineralogical composition, and finally detailed arsenic speciation. Each increasingly detailed analytical method provided further information to explain the effect of soil composition and mineralogy on the bioaccessibility of arsenic.

Effect of organic carbon and soil composition The presence of organic carbon may result in increased arsenic bioaccessibility (19) but the average organic carbon concentration in the 29 samples tested was very low (0.74 wt \%). Two of the three soil samples (MG6 and NB13) contain 
nearly $5 \mathrm{wt} \%$ organic carbon and yet returned arsenic bioaccessibility results consistent with most of the tailings samples. Thus for this sample set, the organic carbon content does not account for variations in arsenic bioaccessibility $(n=29, r=0.03 ; p=0.38)$. Such an effect may require a greater range in organic carbon content, as was previously observed for samples with total organic carbon varying from 0.3 to $40 \mathrm{wt} \%$ (32).

Principal components analysis (SI) was carried out to examine the potential correlation between arsenic bioaccessibility and elemental composition in the sample set. Three groups of samples emerged from this analysis (Figure S3, SI), revealing similarities that were attributed primarily to site location. However, bioaccessibility results varied to the same extent within each group, and no relationship was observed between sample groups and arsenic bioaccessibility. Bulk soil properties did not explain observed variations in arsenic bioaccessibility and a more detailed analysis of the mineralogy of these samples was required.

Bulk Mineralogical Analysis. The major mineral phases in the sample set were identified by XRD analysis (24), and a summary is given in Table S1 (SI). Arsenic-bearing phases were identified in 13 of these samples. The percent arsenic bioaccessibility is very low where the main arsenic-bearing mineral is sparingly soluble. Indeed, less than one percent bioaccessibility was observed for samples CAR2 (dominated by arsenopyrite) and GD1 (dominated by scorodite) (Table 1). Bioaccessibility of the remainder of the samples could not be explained by the bulk XRD analysis, although samples containing calcium carbonate minerals generally showed higher than average bioaccessibility, and the results obtained for these samples in the acidic P1 did not generally increase in $\mathrm{pH}$ neutral $\mathrm{P} 2$. In contrast, the arsenic bioaccessibility of samples without 
carbonate minerals (overall $<10 \%$ arsenic bioaccessibility) generally increased in the $\mathrm{pH}$ neutral P2 (Table 1).

Although this analysis provides useful information on dominant mineralogical characteristics, poorly crystalline or amorphous arsenic-bearing phases could not be identified by conventional $\mathrm{XRD}$ analysis in some samples even where the arsenic concentrations are high. Furthermore, the arsenic bioaccessibility may be influenced by arsenic-bearing phases present in quantities or proportions too small to be detected by conventional XRD. A more sensitive analytical method was required to identify these phases.

Bulk XANES Analysis. X-ray absorption spectroscopy can be a powerful tool for determining arsenic speciation in solid samples and is effective for both amorphous and crystalline materials. Of the 13 samples analyzed (Figure S4, SI), only two (NB8 and NB6C) appear to contain arsenopyrite $\left(\mathrm{As}^{-1}-\mathrm{S}, 11,867.6 \mathrm{eV}\right)$. The XANES spectrum of sample NB6C is consistent with that of arsenopyrite, whereas the spectrum of sample NB8 shows a mixture of arsenopyrite and arsenic in pentavalent form $\left(\mathrm{As}^{+5}-\mathrm{O}, 11,875.3 \mathrm{eV}\right)$. There was no evidence of trivalent arsenic $\left(\mathrm{As}^{+3}-\mathrm{O} 11,871.7 \mathrm{eV}\right)$ in any of the samples tested. The spectra obtained for the other 11 samples (CAR1, CAR5, GD1, MG1, NB1, NB6A, NB7, NB10, NB12, OLD4 and WB1) are consistent with $\mathrm{As}^{+5}-\mathrm{O}$. Previous findings $(33,34)$, indicate that various forms of pentavalent arsenic bound to iron cannot be differentiated by XANES analysis. For example, the calcium-iron arsenate yukonite may represent the major arsenic solid phase in some samples, yet its XANES spectrum is largely analogous to that of scorodite. Nevertheless, XANES analysis confirmed the findings 
for the dominant arsenic phases identified by bulk XRD. Bulk XANES analysis was also effective at identifying unoxidized $\mathrm{As}^{-1}$-S (arsenopyrite) (Figure S4, SI).

Detailed Mineralogical Analysis. Analytical methods described in the previous sections could not explain the bioaccessibility results for most of the samples. Further investigation was carried out (details can be found in Walker et al. (24) to determine the abundance (dominant, major, minor, trace, or not observed) of the arsenic phases present. In the present study, the results of this mineralogical analysis for 19 samples are compared with respect to their measured arsenic bioaccessibility. A summary is presented in Table 2. The arsenic phases belong to seven groups: 1- sulphides (arsenopyrite, realgar $\left(\mathrm{As}_{4} \mathrm{~S}_{4}\right)$, arsenic-bearing pyrite $\left.\left(\mathrm{FeS}_{2}\right)\right)$, 2- iron arsenates (scorodite, amorphous forms, pharmacosiderite $\left(\mathrm{KFe}_{4}\left(\mathrm{AsO}_{4}\right)_{3}(\mathrm{OH})_{4} \bullet 6-7 \mathrm{H}_{2} \mathrm{O}\right)$, kankite $\left(\mathrm{FeAsO}_{4} \cdot 3.5 \mathrm{H}_{2} \mathrm{O}\right)$ ), 3- arsenic-bearing iron (oxy)hydroxides (goethite $(\alpha-\mathrm{FeO}(\mathrm{OH})$ ), lepidocrocite $(\gamma-\mathrm{FeO}(\mathrm{OH}))$, akaganeite $\left(\beta-\mathrm{FeO}(\mathrm{OH}) \bullet \mathrm{xH}_{2} \mathrm{O} \bullet \mathrm{yCl}\right)$, amorphous forms), 4- roastergenerated arsenic-bearing iron oxides (hematite $\left(\alpha-\mathrm{Fe}_{2} \mathrm{O}_{3}\right)$, maghemite $\left.\left(\gamma-\mathrm{Fe}_{2} \mathrm{O}_{3}\right)\right)$, 5- sulphates (tooeleite $\left(\mathrm{Fe}_{6}\left(\mathrm{AsO}_{3}\right)_{4}\left(\mathrm{SO}_{4}\right)(\mathrm{OH})_{4} \bullet 4 \mathrm{H}_{2} \mathrm{O}\right)$, arsenic-bearing jarosite $\left(\mathrm{KFe}^{(+3)}{ }_{3}(\mathrm{OH})_{6}\left(\mathrm{SO}_{4}\right)_{2}\right)$, arsenic-bearing schwertmannite $\left(\mathrm{Fe}^{3+}{ }_{16} \mathrm{O}_{16}(\mathrm{OH})_{12}\left(\mathrm{SO}_{4}\right)_{2}\right)$, 6- undifferentiated clay minerals (generally iron-bearing), and 7- calcium-iron arsenates (yukonite, amorphous forms) (3, 24). In Table 2, the samples are presented in increasing percent arsenic bioaccessibility (from left to right), which allows the approximate ordering of arsenic species from less to more soluble (from top to bottom) based on previous studies of pure mineral phases (7), and according to the results of this study. Within each group, arsenic associated with the amorphous material is generally assumed to be more bioaccessible than a more crystalline form. However, this may not strictly apply in the case of arsenate, which binds to iron oxides and oxyhydroxides in a similar 
arrangement regardless of crystal structure (35). Arsenic in the roaster-derived iron oxides (e.g. hematite) may also exhibit unique characteristics given their complex ore processing history (21, 33).

As previously noted, samples that are dominated by sparingly soluble arsenopyrite (e.g. CAR2) or scorodite (e.g. GD1) have very low percent bioaccessibilities. The very low bioaccessibility results for sample GD1 (predominantly scorodite) are consistent with the low solubility of this phase, and cannot be attributed to limited available surface area since the scorodite in this sample is present as micro- to nano-crystalline aggregates (24). Furthermore, the bioaccessible arsenic concentration of $671 \mathrm{mg} \cdot \mathrm{kg}^{-1}(0.32 \%)$ at the neutral $\mathrm{pH}$ of $\mathrm{P} 2$, compared to only $277 \mathrm{mg} \cdot \mathrm{kg}^{-1}$ $(0.13 \%)$ in $\mathrm{P} 1$ is consistent with the $\mathrm{pH}$ dependent solubility behaviour of pure scorodite (31). In general, the presence of iron arsenates other than scorodite (e.g. kankite, amorphous iron arsenate) and iron oxyhydroxides increases bioaccessibility to between 2 and $7 \%$. The high surface area and texture of these aggregates (24) may contribute significantly to the level of dissolution. However, their relative contributions cannot be discerned from the data given their presence as mixed phases.

The influence of mixed arsenic phases on the bioaccessibility of arsenic is evident when comparing samples CAR2 (predominantly arsenopyrite) and MG4 (small proportion of arsenopyrite) (SI, Table S1). Specifically, the contributions of amorphous iron arsenates and amorphous arsenic-bearing iron (oxy)hydroxides in sample MG4 are sufficient to increase the overall arsenic bioaccessibility to $2.7 \%$ compared to the very low $0.62 \%$ bioaccessibility from the arsenopyrite-rich sample CAR2. Traces of sparingly soluble realgar (36) in sample MG4 are 
not expected to contribute to the increased bioaccessibility. Samples GD2 and OLD4 both contain major iron arsenate phases, but the greater arsenic bioaccessibility in sample OLD4 (9.7\%) may result from a major phase of arsenic-bearing jarosite, which is only found in trace quantities in sample GD2 (4.1\%). For samples with mixtures of less and more soluble phases (even when insoluble arsenic forms are present as major phases) the minor presence of more soluble phases can increase the arsenic bioaccessibility.

Detailed mineralogical analysis confirmed the presence of calcium-iron arsenates as major phases in samples MG3 and GD5 (Table 2), both of which have higher than average percent arsenic bioaccessibility (Table 1). The lower bioaccessibility of arsenic in MG3 compared to GD5 may in part be related to the presence of pharmacosiderite detected as a major phase in MG3, but not GD5. The presence of calcium-iron arsenates was also observed in oxidized calcite-bearing tailings from North Brookfield, along with trace quantities of roaster iron oxides. The elevated percent bioaccessibility in sample NB11A (16\%) may result from two different phases. In this sample, arsenic may be released from the abundant roaster iron oxides (mostly hematite containing $<2 \mathrm{wt} \%$ arsenic), or from the less abundant arsenic-bearing schwertmannite (which typically contains an order of magnitude more arsenic per grain). Sample NB12 is also unique in that it shows no evidence of solid roaster or weathered sulphide products. In this sample, arsenic may have been introduced in soluble form, and is primarily associated with iron, as reaction products or precipitates among clays and phyllosilicates (3). The higher percent arsenic bioaccessibility (29\%) in this sample may result from the high surface area of clay minerals. Some arsenic may be weakly bound to clay and oxide surfaces, compared with stronglybound inner-sphere sites. In the latter case, the arsenic-clay association may be disrupted under both 
gastric (low $\mathrm{pH})$ and intestinal (neutral $\mathrm{pH}$ ) extraction conditions to a greater degree than arsenic bound to iron oxyhydroxides (37).

Based on the detailed mineralogical data, higher percent bioaccessibility results are thus attributed to the presence of arsenic hosted as calcium-iron arsenates, arsenic-bearing schwertmannite, arsenic-bearing jarosite and clay minerals. Among the samples studied, samples GD5 and NB12 stand out because their percent bioaccessibility (49\% and 29\%) are much greater than the next highest result (16\% for sample NB11A). Additional sample characteristics, such as fine overall grain size (silt and clay) and high surface areas of arsenic-bearing grains described earlier, may be factors leading to elevated arsenic bioaccessibility for these samples.

Bioaccessibility and mineralogy data from the present study indicate very low percent arsenic bioaccessibility results where scorodite and arsenopyrite appear alone. Amorphous iron arsenate and arsenic-bearing iron (oxy)hydroxides, even in the presence of sparingly soluble arsenic phases, increase bioaccessibility by an order of magnitude over scorodite and arsenopyrite. The presence of calcium-iron arsenates coincides with the highest percent bioaccessibility among the samples tested, even where relatively insoluble arsenic phases (arsenopyrite) are present (e.g. GD5). In most samples, the presence of a more soluble arsenic phase, however minor, increases the overall arsenic bioaccessibility. These results are consistent with previous findings, where the small intestine bioaccessibility of arsenic was found to be an order of magnitude greater for a calcium-iron arsenate-bearing sample (GD site) than a scorodite and iron arsenate sample (MG site) (38). 
Samples with similar arsenic mineral phase compositions may exhibit different arsenic bioaccessibilities. These variations may be attributed to different proportions of the mixed arsenic phases present as well as to the texture and grain size distribution within the $<150 \mu \mathrm{m}$ particle size fraction. Despite the complexity of the mixed arsenic phases identified in this study, clear geochemical trends (e.g. importance of carbonate buffered vs. acidic tailings) emerge from this study that may be applicable to other sites. Furthermore, weathering processes in geochemically young materials (such as tailings) may result in changes in mineralogy (24) and associated arsenic bioaccessibility over a time scale relevant to risk assessment.

The elevated bioaccessible arsenic concentrations reported for tailings and soils in the present study highlight potential risks to human health, and even the lowest percent arsenic bioaccessibilities may reflect risks where total arsenic is present in high concentrations. The mineralogical data presented help to explain the trends observed in arsenic release during bioaccessibility tests. The very low organic carbon content in the mine tailings did not affect the bioaccessibility of arsenic in the present study; however, soil amendments (e.g. increased organic carbon content, or liming) may lead to increased bioaccessibility. Liming could provide a labile source of calcium at neutral $\mathrm{pH}$ and lead to alteration of iron-arsenates to calcium-iron arsenates with a corresponding increase in arsenic bioaccessibility. When combined with site-specific bioaccessibility measurements, the results from this study can be used to better understand the risks associated with exposure to arsenic in tailings and soil.

\section{Acknowledgements}

The authors wish to thank A. Campbell, L. Easton, J. Harris, and K. House for their help with sample analysis, and the Davies Charitable Foundation for post-doctoral support of SRW. The 
authors gratefully acknowledge the support of the National Science and Engineering Research Council via the Metals in The Human Environment Strategic Network (a full list of sponsors at www.mithe-sn.org) and a Discovery Grant (to KJR), and the APS PNC/XOR, in particular R. Gordon. The PNC/XOR facilities, and research at these facilities, are supported by the US Department of Energy (DOE) - Basic Energy Sciences, a major facilities access grant from NSERC, the University of Washington, Simon Fraser University and APS. Use of APS resources is also supported by the US DOE, Office of Science, Office of Basic Energy Sciences, (Contract DE-AC02-06CH11357). The authors also thank A. Lanzirotti for guidance in conducting $\mu$-XRF, $\mu$-XRD analyses performed at Beamline X26A, NSLS, Brookhaven National Laboratory. X26A

is supported by the US DOE - Geosciences (DE-FG02-92ER14244 to The University of Chicago - CARS) and the Office of Biological and Environmental Research, Environmental Remediation Sciences Division (DE-FC09-96-SR18546 to the University of Georgia). Use of NSLS was supported by DOE under Contract DE-AC02-98CH10886. The authors are grateful to P. Hunt of Natural Resources Canada for assisting in the ESEM analyses. This is contribution number 20090357 of the Earth Sciences Sector, Natural Resources Canada.

\section{Supporting Information Available}

Two tables and four figures are provided as supporting information (SI). This material is available free of charge via the Internet at http://pubs.acs.org.

\section{Literature Cited.}

(1) Ryan, R.J.; Smith, P.K. A review of the mesothermal gold deposits of the Meguma Group, Nova Scotia, Canada. Ore Geol. Rev. 1998. 13:153-183. 
(2) Wong, H.K.T.; Gauthier, A.; Nriagu, J.O. Dispersion and toxicity of metals from abandoned gold mine tailings at Goldenville, Nova Scotia, Canada. Sci. Total Environ. 1999, 228, 35-47.

(3) Parsons, M.B.; Walker, S.R.; Jamieson, H.E.; Hall, G.E.M.; Vaive, J.E.; LeBlanc, K.W.G. Chemical and mineralogical characterization of arsenic and associated elements in tailings and soils from five historical gold mining districts in Nova Scotia - Open File. 2010.

(4) Canadian Council of Ministers of the Environment (CCME) Canadian soil quality guidelines for the protection of environmental and human health: arsenic (inorganic) fact sheet. CCME 1997, 1-7.

(5) Nova Scotia Environmental and Labour (NSEL). Guidelines for management of contaminated sites in Nova Scotia. Nova Scotia Environment, Halifax, NS, Canada. 1996, (updated 2004). 19p.

(6) Rodriguez, R.R.; Basta, N.T.; Casteel, S.W.; Pace, L.W. An In vitro gastrointestinal method to estimate bioavailable arsenic in contaminated soils and solid media. Environ. Sci. Technol. 1999, 33, 642-649.

(7) Ruby, M.V.; Schoof, R.; Brattin, W.; Goldade, M.; Post, G.; Harnois, M.; Mosby, D.E.; Casteel, S.W.; Berti, W.; Carpenter, M.; Edwards, D.; Cragin, D.; Chappell, W. Advances in evaluating the oral bioavailability of inorganics in soil for use in human health risk assessment. Environ. Sci. Technol. 1999, 33, 3697-3705.

(8) Agency for Toxic Substances and Disease Registry (ATSDR) Toxicological Profile for Arsenic. Department of Health and Human Services, Public Health Services, Atlanta, GA, USA. 2005. 
(9) Richardson, G.M.; Bright, D.A.; Dodd, M. Do current standards of practice in Canada measure what is relevant to human exposure at contaminated sites? II: Oral bioaccessibility of contaminants in soil. Human Ecol. Risk Assess. 2006, 12, 606.

(10) Ruby, M.V.; Davis, A.; Schoof, R.; Eberle, S.; Sellstone, C.M. Estimation of lead and arsenic bioavailability using a physiologically-based extraction test. Environ. Sci. Technol. 1996, 30, 422-430.

(11) Cave, M.R.; Wragg, J.; Palumbo, B.; Klinck, B.A. Measurement of the bioaccessibility of arsenic in UK soils. British Geological Survey. Environment Agency. Nottingham, UK. 2002, P5-062/TR02, 103p.

(12) Koch, I.; Sylvester, S.; Lai, V.W.-.; Owen, A.; Reimer, K.J.; Cullen, W.R. Bioaccessibility and excretion of arsenic in Niu Huang Jie Du Pian pills. Toxicol. Appl. Pharmacol. 2007, 222, 357-364.

(13) Bruce, S.; Noller, B.; Matanitobua, V.; Ng, J. In vitro physiologically based extraction test (PBET) and bioaccessibility of arsenic and lead from various mine waste materials. J. Toxicol. Environ. Health, Part A. 2007, 70, 1700.

(14) Reeder, R.J.; Schoonen, M.A.A.; Lanzirotti, A. Metal speciation and its role in bioaccessibility and bioavailability. Rev. Mineral. Geochem. 2006, 64, 59-113.

(15) Hamel, S.C.; Buckley, B.; Lioy, P.J. Bioaccessibility of metals in soils for different liquid to solid ratios in synthetic gastric fluid. Environ. Sci. Technol. 1998, 32, 358-362.

(16) Bright, D.A.; Richardson, G.M.; Dodd, M. Do current standards of practice in Canada measure what is relevant to human exposure at contaminated sites? I: A discussion of soil particle size and contaminant partitioning in soil. Human Ecol. Risk Assess. 2006, 12, 591. 
(17) Grøn, C.; Andersen, L. Human bioaccessibility of heavy metals and PAH from soil. DHI Water and Environment. Danish Environmental Protection Agency. 2003, No. 8402003.

(18) Beak, D.G.; Basta, N.T.; Scheckel, K.G.; Traina, S.J. Bioaccessibility of arsenic(V) bound to ferrihydrite using a simulated gastrointestinal system. Environ. Sci. Technol. 2006, 40, 13641370.

(19) Dobran, S.; Zagury, G.J. Arsenic speciation and mobilization in CCA-contaminated soils: Influence of organic matter content. Sci. Total Environ. 2006, 364, 239-250.

(20) Malcolm, W. Gold fields of Nova Scotia. Geological Survey of Canada. 1929, Memoir 156 (reprinted in 1976 as Memoir 385), 253p.

(21) Forbes, H.L. The chlorination of gold ore of the North Brookfield Mine, Nova Scotia. J. Can. Mining Inst. 1904, VII, 308-318.

(22) Duggan, M.J.; Inskip, M.J.; Rundle, S.A.; Moorcroft, J.S. Lead in playground dust and on the hands of schoolchildren. Sci. Total Environ. 1985, 44, 65-79.

(23) Smith, P.G.; Koch, I.; Gordon, R.A.; Mandoli, D.F.; Chapman, B.D.; Reimer, K.J. X-ray absorption near-edge structure analysis of arsenic species for application to biological environmental samples. Environ. Sci. Technol. 2005, 39, 248-254.

(24) Walker, S.R.; Parsons, M.B.; Jamieson, H.E.; Lanzirotti, A. Arsenic mineralogy of nearsurface tailings and soils: Influences on arsenic mobility and bioaccessibility in the Nova Scotia gold mining districts. Can. Mineral. 2009, 47, 533-556.

(25) Koch, I.; Duso, A.; Haug, C.; Miskelly, C.; Sommerville, M.; Smith, P.; Reimer, K.J.

Distinguishing between naturally and anthropogenically elevated arsenic at an abandoned arctic military site. Environ. Foren. 2005, 6, 335. 
(26) National Institute of Standards and Technology (NIST). Certificate of analysis - Standard reference material 2710. NIST. Gaithersburg, MD, USA. 2003, 6p.

(27) Smith, P.G.; Koch, I.; Reimer, K.J. Uptake, transport and transformation of arsenate in radishes (Raphanus sativus). Sci. Total Environ. 2008, 390, 188-197.

(28) Palumbo-Roe, B.; Klinck, B. Bioaccessibility of arsenic in mine waste-contaminated soils: A case study from an abandoned arsenic mine in SW England (UK). J. Environ. Sci. Health, Part A. 2007, 42, 1251.

(29) Freeman, G.B.; Johnson, J.D.; Killinger, J.M.; Liao, S.C.; Davis, A.O.; Ruby, M.V.;

Chaney, R.L.; Lovre, S.C.; Bergstrom, P.D. Bioavailability of arsenic in soil impacted by smelter activities following oral administration in rabbits. Fund. Appl. Toxicol. 1993, 21, 83-88.

(30) National Environmental Policy Institute (NEPI). Bioavailability policy project phase II: metals task force report. Washington, DC, USA. 2000, 122p.

(31) Langmuir, D.; Mahoney, J.; Rowson, J. Solubility products of amorphous ferric arsenate and crystalline scorodite $\left(\mathrm{FeAsO}_{4} \cdot 2 \mathrm{H}_{2} \mathrm{O}\right)$ and their application to arsenic behavior in buried mine tailings. Geochim. Cosmochim. Acta 2006, 70, 2942-2956.

(32) Girouard, E.; Zagury, G.J. Arsenic bioaccessibility in CCA-contaminated soils: Influence of soil properties, arsenic fractionation, and particle-size fraction. Sci. Total Environ. 2009, 407, 2576-2585.

(33) Walker, S.R.; Jamieson, H.E.; Lanzirotti, A.; Andrade, C.F.; Hall, G.E.M. The speciation of arsenic in iron oxides in mine wastes from the Giant gold mine, NWT: Application of synchrotron micro-XRD and micro-XANES at the grain scale. Can. Mineral. 2005, 43, $1205-$ 1224. 
(34) Zielinski, R.A.; Foster, A.L.; Meeker, G.P.; Brownfield, I.K. Mode of occurrence of arsenic in feed coal and its derivative fly ash, Black Warrior Basin, Alabama. Fuel 2007, 86, 560-572. (35) Sherman, D.M.; Randall, S.R. Surface complexation of arsenic(V) to iron(III) (hydr)oxides: structural mechanism from ab initio molecular geometries and EXAFS spectroscopy. Geochim. Cosmochim. Acta 2003, 67, 4223-4230.

(36) Liu, J.; Lu, Y.; Wu, Q.; Goyer, R.A.; Waalkes, M.P. Mineral arsenicals in traditional medicines: Orpiment, realgar, and arsenolite. J. Pharmacol. Exp. Ther. 2008, 326, 363-368. (37) Goldberg, S. Competitive adsorption of arsenate and arsenite on oxides and clay minerals. Soil Sci. Soc. Am. J. 2002, 66, 642-649.

(38) Laird, B.D.; Van, de Wiele.; Corriveau, M.C.; Jamieson, H.E.; Parsons, M.B.; Verstraete, W.; Siciliano, S.D. Gastrointestinal microbes increase arsenic bioaccessibility of ingested mine tailings using the simulator of the human intestinal microbial ecosystem. Environ. Sci. Technol. 2007, 41, 5542-5547. 
Figures and Tables

\begin{tabular}{|c|c|c|c|c|c|}
\hline \multirow[t]{2}{*}{ sample $^{\text {b }}$} & \multirow[t]{2}{*}{$\begin{array}{l}\text { total arsenic } \\
\text { concentration } \\
\left(\mathbf{m g}^{\circ} \mathbf{k g}^{-1}\right)\end{array}$} & \multicolumn{2}{|c|}{$\begin{array}{l}\text { bioaccessible arsenic } \\
\text { concentration } \\
\left(\mathrm{mg}^{\mathrm{c}} \mathrm{kg}^{-1} \text { dry weight) }\right.\end{array}$} & \multicolumn{2}{|c|}{$\begin{array}{c}\text { percent arsenic } \\
\text { bioaccessibility }^{\mathrm{d}} \\
(\%)\end{array}$} \\
\hline & & P1 & P2 & P1 & P2 \\
\hline CAR1 & 77,000 & 1,600 & 3,800 & 2.1 & 5.0 \\
\hline CAR2 & 310,000 & 1,900 & 850 & 0.62 & 0.27 \\
\hline CAR3 & 21,000 & 620 & 1,400 & 2.9 & 6.8 \\
\hline CAR4 & 15,000 & 590 & 1,000 & 3.9 & 6.5 \\
\hline CAR5 & 73,000 & 340 & 1,000 & 0.50 & 1.4 \\
\hline GD1 & 210,000 & 280 & 670 & 0.13 & 0.32 \\
\hline GD2 & 19,000 & 460 & 790 & 2.4 & 4.1 \\
\hline GD3 & 39,000 & 620 & 1,300 & 1.6 & 3.3 \\
\hline GD4 & 49,000 & 600 & 1,200 & 1.2 & 2.5 \\
\hline GD5 & 7,200 & 3,400 & 3,500 & 47 & 49 \\
\hline MG1 & 62,000 & 1,300 & 2,300 & 2.1 & 3.7 \\
\hline MG2 & 24,000 & 440 & 810 & 1.8 & 3.4 \\
\hline MG3 & 24,000 & 2,700 & 2,800 & 11 & 12 \\
\hline MG4 & 21,000 & 430 & 580 & 2.0 & 2.7 \\
\hline MG6 & 320 & 8.0 & 4.0 & 2.5 & 1.4 \\
\hline NB1 & 410 & 100 & 100 & 24 & 25 \\
\hline NB3 & 650 & 140 & 150 & 22 & 24 \\
\hline NB6A & 740 & 120 & 130 & 16 & 18 \\
\hline NB6B & 7,200 & 280 & 410 & 3.9 & 5.6 \\
\hline NB6C & 6,300 & 30 & 28 & 0.48 & 0.44 \\
\hline NB7 & 460 & 140 & 160 & 31 & 34 \\
\hline NB8 & 890 & 110 & 100 & 12 & 11 \\
\hline NB10 & 2,300 & 450 & 550 & 20 & 24 \\
\hline NB11A & 6,800 & 950 & 1,100 & 14 & 16 \\
\hline NB11B & 5,300 & 810 & 1,400 & 16 & 26 \\
\hline NB12 & 9,200 & 1,200 & 2,700 & 13 & 29 \\
\hline NB13 & 200 & 21 & 32 & 11 & 17 \\
\hline OLD4 & 34,000 & 1,400 & 3,300 & 4.2 & 9.7 \\
\hline WB1 & 19,000 & 1,600 & 3,500 & 8.3 & 19 \\
\hline \multicolumn{6}{|c|}{$\begin{array}{l}{ }^{\mathrm{a}} \text { Test results for the }<150 \mu \mathrm{m} \text { particle size fraction. }{ }^{\mathrm{b}} \text { Bold script indicates sample } \\
\text { containing calcium carbonates, where similar results were noted between P1 and } \\
\mathrm{P} 2 .{ }^{\mathrm{c}} \mathrm{P} 1=\text { Phase } 1 \text { (gastric); P2 }=\text { Phase } 2 \text { (gastric }+ \text { intestinal). }{ }^{\mathrm{d}} \text { Calculated as } \\
100 \cdot \text { bioaccessible arsenic concentration } \bullet \text { (total arsenic concentration) })^{-1}\end{array}$} \\
\hline
\end{tabular}


Table 2. Arsenic mineralogy and bioaccessibility ${ }^{\mathrm{a}}$.

sample (percent bioaccessible arsenic)

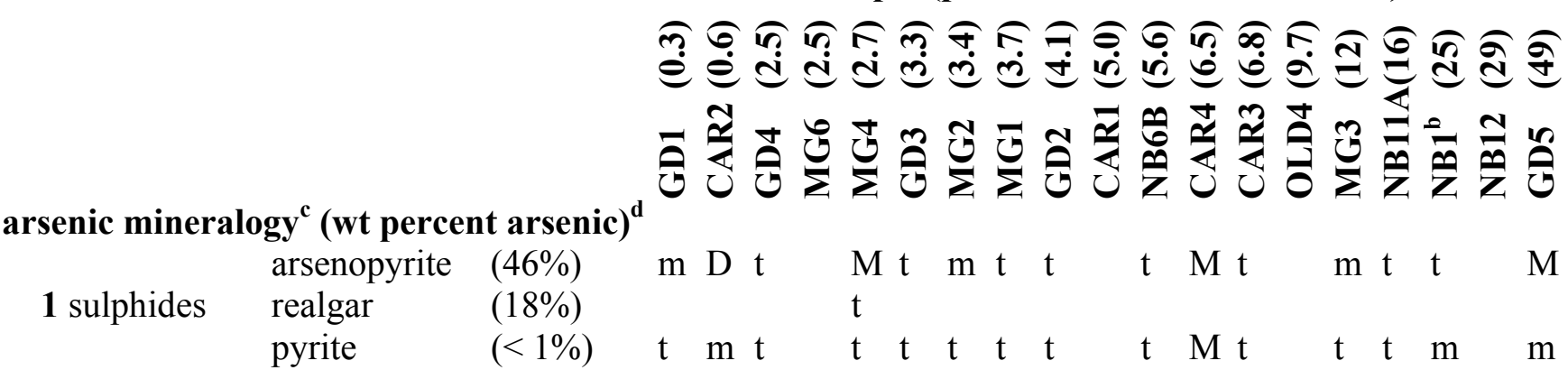

arsenic mineralogy ${ }^{c}$ (wt percent arsenic) ${ }^{d}$

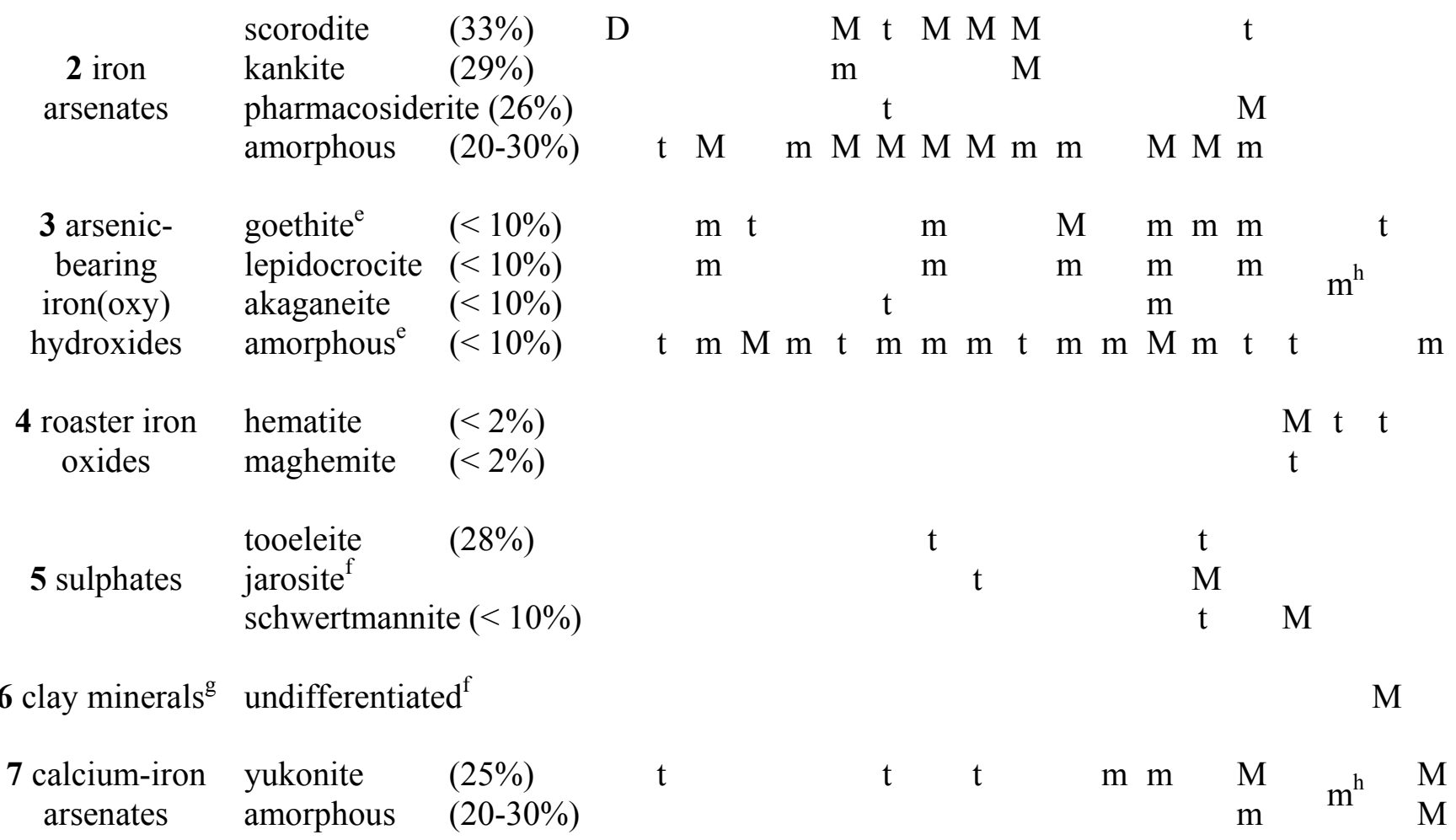

${ }^{a}$ Arsenic mineral phases are presented in order of their increasing contribution to arsenic bioaccessibility (numbers 1 to 7), based on the empirical results of this study; qualitative abundance for each arsenic phase is indicated as $\mathrm{D}=$ dominates sample; $\mathrm{M}=$ major; $\mathrm{m}=$ minor; $\mathrm{t}=$ trace amounts observed. ${ }^{\mathrm{b}}$ Mineral determination for NB1 is by petrography and ESEM only. ${ }^{c}$ For samples containing calcium-iron arsenates, the iron oxyhydroxides also bear calcium. ${ }^{\mathrm{d}}$ Weight percent arsenic concentration is determined experimentally, except for arsenopyrite, realgar, scorodite, kankite and tooeleite, for which the stoichiometric values are given. ${ }^{\mathrm{e}}$ Arsenic content of these phases in sample MG6 is $<1 \mathrm{wt} \%$. ${ }^{\mathrm{f}}$ Amount of arsenic in these phases was not determined. ${ }^{\mathrm{g}}$ Generally iron-bearing clay minerals. Clay mineral associated arsenic was identified as a major phase in NB12. This association may be present as a trace or minor phase in other samples. ${ }^{\mathrm{h}}$ Undifferentiated arsenic mineral within each arsenic-bearing phase. 


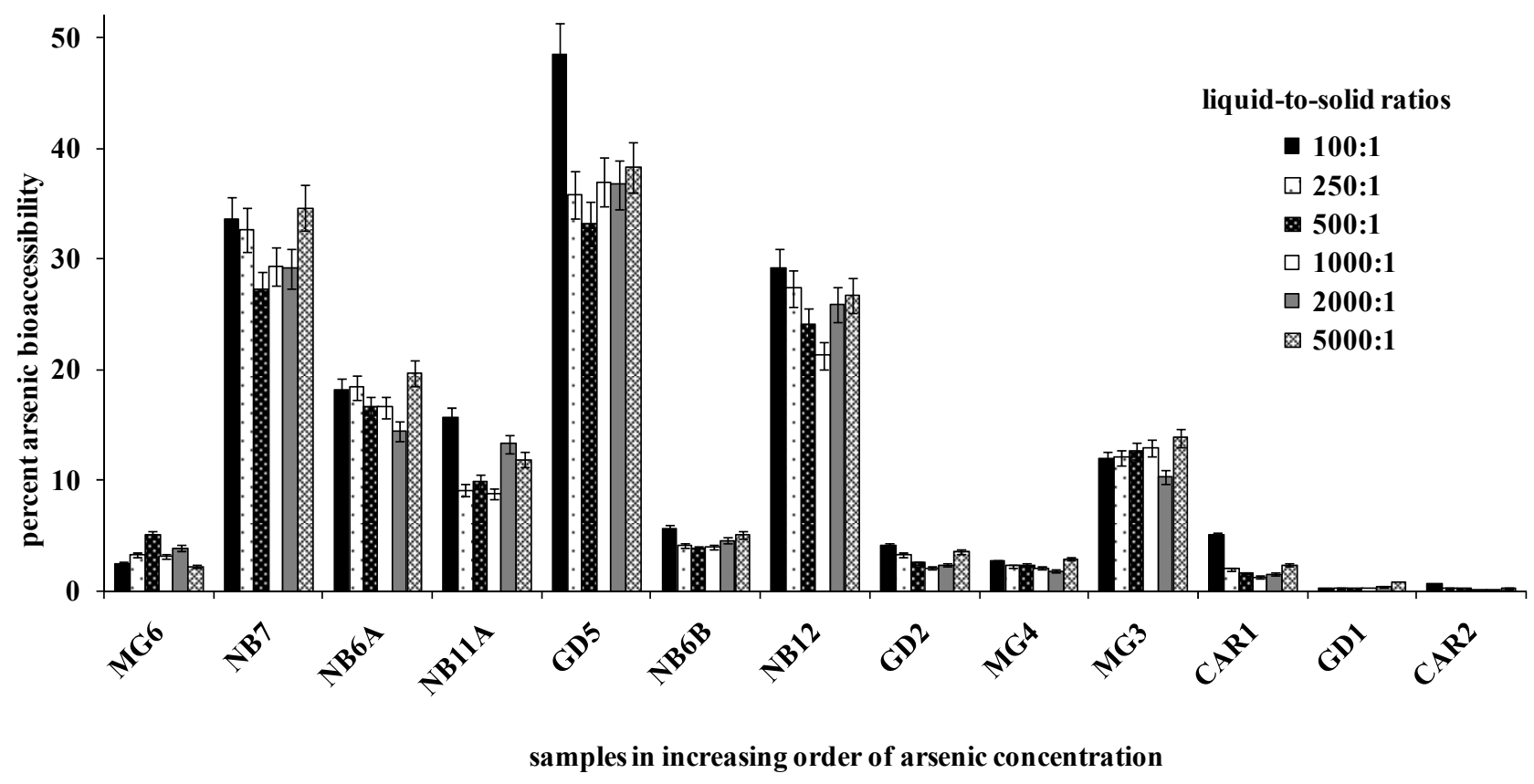

Figure 1. Liquid-to-solid ratio comparison for the percent arsenic bioaccessibility in selected samples (abbreviations are described in the text). Results for the $<150 \mu \mathrm{m}$ particle size fraction tested at 100:1, 250:1, 500:1, 1000:1, 2000:1 and 5000:1 liquid-to-solid ratios are presented for the higher value of either the gastric (P1) or the gastric + intestinal phase (P2) in each case. The value for $P 2$ was selected in $96 \%$ of cases for this series of tests. Error bars $( \pm 7.2 \%)$ represent the average of the relative percent difference between duplicates. 


\section{Brief}

The more soluble arsenic phases exert the greatest influence on the bioaccessibility of arsenic in tailings and soil samples containing a complex mixture of arsenic minerals. 